\title{
Use of Weather Variables to Quantify Sorghum Ergot Potential in South Africa
}

\author{
N. W. McLaren and B. C. Flett, Agricultural Research Council-Grain Crops Institute, Private Bag X1251, \\ Potchefstroom, 2520, Republic of South Africa
}

\begin{abstract}
McLaren, N. W., and Flett, B. C. 1998. Use of weather variables to quantify sorghum ergot potential in South Africa. Plant Dis. 82:26-29.

Quantification of resistance to ergot requires that the observed ergot severity within a sorghum line be compared with expected ergot severity (ergot potential) to compensate for differences in environmental favorability for the disease among flowering dates and seasons. The ergot potential required to induce the onset of disease is referred to as the ergot breakdown point of that line. In earlier studies, the ergot potential of a specific flowering date was defined as the mean ergot severity in all sorghum heads over all lines in the nursery which commenced flowering on that date in a genetically broad-based sorghum nursery. In this study, results of field trials enabled accurate prediction of ergot potential by using a multiple regression analysis which included three weather variables - namely, pre-flowering minimum temperature (mean of days 23 to 27 pre-flowering), mean daily maximum temperature, and mean daily maximum relative humidity (mean of days 1 to 5 post-flowering; $R^{2}=0.90 ; P=0.91 \mathrm{E}-5$ ). Evaluation of predicted and observed ergot severity in an independent data set gave an index of agreement of $d=0.94$ and $R^{2}=0.84(P=0.106 \mathrm{E}-4)$, showing that ergot severity, assuming the presence of viable inoculum, can be accurately predicted. Low pre-flowering minimum temperature was associated with reduced pollen viability, which appeared to be the primary factor predisposing lines to ergot.
\end{abstract}

Additional keywords: Claviceps africana, Sorghum bicolor, sugary disease

Ergot (sugary disease) of sorghum (Sorghum bicolor (L.) Moench), caused by Claviceps africana Frederickson, Mantle and de Milliano, is a disease of unfertilized sorghum ovaries. The stigma is the principal site of infection, although conidia may germinate and infect through the style and ovary wall (7). Thus, tissues are only susceptible to infection from floral gaping, just before or at anthesis $(6,8)$. Subsequent to effective pollination and fertilization susceptibility declines rapidly, and several studies have shown that effective pollination and fertilization make pistils escape or resist ergot $(8,13)$. Thus, the infection window is of limited duration and depends on flowering behavior of the host plant $(1,2)$, predisposition by reduced pollen viability resulting from pre-flowering cold stress (12), and weather conditions during early flowering $(11,12,14)$.

Cold stress (temperatures below $13^{\circ} \mathrm{C}$ ) 3 to 4 weeks prior to flowering reduces pollen viability $(3,4)$ which, in turn, predisposes sorghum to infection by reducing self-pollination ability (12). Moderate temperatures during anthesis, i.e. with mean daily maximum temperatures below

Corresponding author: N. W. McLaren

E-mail: Neal@igg2.agric.za

Accepted for publication 9 September 1997.

Publication no. D-1997-1103-02R

(C) 1998 The American Phytopathological Society $28^{\circ} \mathrm{C}$ and an optimum of $19.5^{\circ} \mathrm{C}$, promote infection and disease development (11).

Variation in ergot incidence and severity in sorghum lines is related to tolerance of lines to ergot-favorable conditions, such as pre-flowering cold stress and the ability to escape infection by ensuring effective and rapid pollination (1). Escape resistance of a specific line is quantified by comparing observed ergot severities associated with different flowering dates (date of commencement of anthesis) with the ergot potential of those dates (10). Ergot potential of a flowering date at a locality was defined as the mean ergot severity in all heads which flowered on that specific date in a genetically broad-based sorghum nursery. The ergot potential required to induce the onset of disease in the test line is determined by regressing observed disease severity on disease potential (onset of disease being quantified using an arbitrary disease severity, usually $1 \%$ or $5 \%$ ) and is termed the ergot breakdown point (10). Since ergot severity is sensitive to changes in weather during early post-anthesis, this methodology compensates for differences in environmental favorability for the disease among flowering dates and seasons.

Ergot potential as previously applied in sorghum screening trials (10) is not a fixed value, but varies according to the genetic base of the sorghum nursery used in its calculation. Thus, ergot breakdown points of lines from different areas cannot be compared unless base populations used to determine ergot potentials are similar.
Furthermore, many diverse lines need to be evaluated, and at least five disease epidemics ranging from low (less than 5\%) to high (more than 40\%) disease severities need to be created for accurate application of regression techniques for the determination of ergot breakdown point, thus increasing field, time, and labor requirements. The present study was conducted to determine whether ergot potential could be quantified on the basis of pre- and early post-flowering weather conditions.

\section{MATERIALS AND METHODS}

Model development. Sorghum (179 male-normal lines) was planted in singlerow plots at Potchefstroom (North-West Province) and Bethlehem (Free State) during the 1990 to 1991 and 1992 to 1993 seasons. The collection included lines from Texas, Nebraska, Iowa, International Crops Research Institute for the Semi-Arid Tropics (ICRISAT), and southern Africa and included a wide range of genetic variability. Each plot contained approximately 60 plants in rows $6 \mathrm{~m}$ in length and spaced $1.2 \mathrm{~m}$ apart. The trial was replicated three times. Planting of replicates was split over three planting dates spaced from mid-November to early January to ensure a range of flowering dates. Planting dates at Bethlehem were 24 November, 14 December, and 3 January during 1990 to 1991, and 21 November, 20 December, and 4 January during 1992 to 1993. At Potchefstroom, trials were planted on 22 November, 12 December, and 6 January during 1990 to 1991 and on 19 November, 17 December, and 8 January during 1992 to 1993 . Plots were fertilized with $300 \mathrm{~kg} \mathrm{ha}^{-1} 6.3 \mathrm{~N}-9.4 \mathrm{P}-$ $6.3 \mathrm{~K}$ prior to planting, and maintained until flowering with insect and weed control and irrigation applied as required.

At flowering $( \pm 10 \%$ pollen shed), sorghum heads were sprayed until run-off with a spore suspension of $C$. africana in water (approximately $10^{4}$ spores per $\mathrm{ml}$, determined with a hemacytometer). Spores were washed from previously infected heads of greenhouse grown male-sterile plants with fresh exudate. Ten random heads per line were inoculated at weekly intervals on three to four different flowering dates per locality during each season as new flushes of flowers became available. Flowering ranged from early February to early April. Each head was labeled with the respective flowering and inoculation date.

At both localities, pollen from 10 uninoculated heads per line was shaken 
onto a glass slide containing a drop of $2 \%$ $\mathrm{KI}$, and examined microscopically for starch content. Grains stained blue-black (indicating the presence of starch) were counted as viable and amber grains (indicating an absence of starch) as nonviable. An average of 50 random pollen grains per head were counted, and the mean percentage viable pollen per line for each flowering date was calculated.

At the soft dough stage of grain development, the percentage of ergot-infected florets per head (i.e., those exuding honeydew) was estimated visually. The mean percentage diseased florets per line was calculated for each flowering date. The ergot potential associated with each flowering date was determined as the mean ergot severity over all lines associated with that particular flowering date. The number of lines that commenced pollen shed on specific flowering dates differed due to seasonal requirements, and only those flowering dates that yielded more than 40 lines per flowering/inoculation date were included in the study. were monitored at First Order weather stations, run jointly by South African Weather Bureau and the ARC-Institute for Soil, Climate, and Water at each locality. Instrumentation and layout were according to World Meteorological Organization Standards. Stations were located within $400 \mathrm{~m}$ of trials at Bethlehem and 1,200 m
Weather data for the duration of the trial

at Potchefstroom. Pentad values (mean of 5 consecutive days) of maximum and minimum temperature, maximum and minimum relative humidity, rainfall, evaporation, and sunshine hours were recorded. Correlation analyses (Statgraphics 7) were conducted to determine the relationship between pentad values and ergot potential. Multiple regression analysis (Borland, Eureka) was used to determine variables which contributed significantly $(P<0.05)$ to variation in ergot potential.

Model verification. The ergot potential prediction model was verified using 100 sorghum lines with different degrees of susceptibility. Lines were planted at Potchefstroom and Bethlehem during the 1994 to 1995 and 1995 to 1996 seasons using the above trial procedure for ergot evaluation. Expected ergot severities, based on the ergot potential prediction model, were compared with observed ergot severities. The relationship between predicted ergot potential (i.e., based on weather variables) and observed ergot potential (i.e., mean of all lines within a flowering date) were compared using difference measures suggested by Willmott (18).

\section{RESULTS}

No significant correlations $(P \leq 0.05$, $12 d f$ ) were recorded between mean ergot severity and pentad values for daily sunshine hours, evaporation, rainfall, or num-

Table 1. Correlations between mean ergot severity caused by Claviceps africana in a genetically broad-based sorghum population and pentad values of mean minimum and maximum temperature and maximum relative humidity during 1990 to 1991 and 1992 to 1993 growing seasons in South Africa

\begin{tabular}{|c|c|c|c|c|c|}
\hline \multicolumn{2}{|c|}{$\begin{array}{c}\text { Mean minimum } \\
\text { temperature }\end{array}$} & \multicolumn{2}{|c|}{$\begin{array}{c}\text { Mean maximum } \\
\text { temperature }\end{array}$} & \multicolumn{2}{|c|}{$\begin{array}{c}\text { Mean relative maximum } \\
\text { humidity }\end{array}$} \\
\hline $\begin{array}{l}\text { Days before } \\
\text { anthesis }\end{array}$ & $r$ & $\begin{array}{l}\text { Days after } \\
\text { anthesis }\end{array}$ & $r$ & $\begin{array}{l}\text { Days after } \\
\text { anthesis }\end{array}$ & $r$ \\
\hline $26-30$ & -0.58 & $0-4$ & -0.28 & $0-4$ & 0.61 \\
\hline $25-29$ & $-0.68^{* z}$ & $1-5$ & $-0.81 *$ & $1-5$ & $0.82^{*}$ \\
\hline $24-28$ & $-0.74 *$ & $2-6$ & $-0.75^{*}$ & $2-6$ & $0.73^{*}$ \\
\hline $23-27$ & $-0.79 *$ & $3-7$ & $-0.73^{*}$ & $3-7$ & $0.70 *$ \\
\hline $22-26$ & $-0.73^{*}$ & $4-8$ & $-0.65^{*}$ & $4-8$ & 0.63 \\
\hline $21-25$ & $-0.70^{*}$ & $5-9$ & -0.62 & $5-9$ & 0.52 \\
\hline $20-24$ & $-0.65^{*}$ & $6-10$ & -0.64 & $6-10$ & 0.19 \\
\hline $19-23$ & -0.63 & & & & \\
\hline
\end{tabular}

$\mathrm{z} *$ denotes $P<0.01$. ber of rainy days at any stage of crop development. These variables were, therefore, ignored in model development Highest correlations were obtained between mean ergot severity and mean minimum temperature 23 to 27 days before flower opening, mean maximum temperature during days 1 to 5 post-flowering, and mean maximum relative humidity during days 1 to 5 post-flowering (Table 1).

The variables mean minimum temperature 23 to 27 days before flower opening, mean maximum temperature during days 1 to 5 post-flowering, and mean maximum relative humidity during days 1 to 5 postflowering were included in a multiple regression analysis based on previously determined relationships $(11,12)$. This yielded the model $Y=\left(-3.229 \times X_{1}\right)+$ EXP $\left(-0.0029 \times X_{2} \times X_{2}+0.0936 \times X_{2}+\right.$ $3.061)+\left(0.379 \times X_{3}\right)$, where $Y=$ expected mean ergot severity in a genetically broadbased sorghum population (ergot potential), $X_{1}=$ mean minimum temperature $\left({ }^{\circ} \mathrm{C}\right) 23$ to 27 days before flowering, $X_{2}=$ mean daily maximum temperature $\left({ }^{\circ} \mathrm{C}\right) 1$ to 5 days after flowering, and $X_{3}=$ mean daily maximum relative humidity $\left({ }^{\circ} \mathrm{C}\right) 1$ to 5 days after flowering.

The model accounted for close to $90 \%$ of the variation in disease severity $\left(R^{2}=\right.$ $0.898, P=0.91 \mathrm{E}-5)$. The model was applied to flowering dates and respective weather data collected during the 1994 to 1995 and 1995 to 1996 seasons. Analysis of predicted and observed ergot potentials according to Willmott (18) yielded a high index of agreement $\left(d=0.94, R^{2}=0.84, P\right.$ $<0.106 \mathrm{E}-4$; Table 2). The low root mean square errors $\left(\mathrm{RMSE}_{\text {(systematic) }}=2.32\right.$ and $\operatorname{RMSE}_{\text {(unsystematic) }}=3.67$ ) further support the accuracy of the model in predicting ergot potential in an artificially inoculated, genetically broad-based population.

Mean pollen viability was highly correlated with pre-flowering minimum temperature $\left(R^{2}=0.79, P=0.13 \mathrm{E}-4\right.$; Fig. 1$)$. The relationship between pollen viability and ergot potential is illustrated in Figure 2 . The significant relationship between these variables $\left(R^{2}=0.64, P=0.29 \mathrm{E}-2\right)$ showed induced sterility by weather variables to be associated with increased ergot susceptibility.

Table 2. Quantitative measures of the relationship between predicted ergot potential determined according to weather during pre-and early post-flowering of sorghum and observed ergot potential in field trials during 1994 to 1995 and 1995 to 1996 growing seasons in South Africa

\begin{tabular}{|c|c|c|c|c|c|c|c|c|c|c|c|}
\hline$O^{q}$ & $P^{r}$ & $s_{0}{ }^{\mathrm{s}}$ & $s_{\mathrm{p}}{ }^{\mathrm{t}}$ & $N^{\mathrm{u}}$ & $a^{v}$ & $b$ & MAE $^{\mathbf{w}}$ & $\operatorname{RMSE}_{\mathrm{a}}^{\mathbf{x}}$ & $\mathrm{RMSE}_{\mathrm{u}}$ & $d^{y}$ & $R^{2 \mathrm{z}}$ \\
\hline 32.54 & 34.84 & 8.88 & 9.29 & 13 & 0.88 & 1.97 & 3.67 & 2.32 & 3.67 & 0.94 & 0.84 \\
\hline $\begin{array}{l}\text { व } O=\mathrm{m} \\
{ }^{\mathrm{r}} P=\mathrm{m} \\
{ }^{\mathrm{s}} s_{\mathrm{o}}=\mathrm{st} \\
{ }^{\mathrm{t}} S_{\mathrm{p}}=\mathrm{st} \\
{ }^{\mathrm{u}} N=\mathrm{n} \\
{ }^{\mathrm{v}} a, b= \\
{ }^{\mathrm{w}} \mathrm{MAE} \\
{ }^{\mathrm{c}} \mathrm{RMSE} \\
{ }^{\mathrm{y}} d=\mathrm{in} \\
{ }^{\mathrm{z}} R^{2}=\mathrm{r}\end{array}$ & $\begin{array}{l}\text { bserved } \\
\text { redicted } \\
\text { deviatio } \\
\text { deviatio } \\
\text { f observ } \\
\text { ion para } \\
\text { average } \\
\mathrm{E}_{\mathrm{u}}=\text { roc } \\
\text { greemer } \\
\text { n param }\end{array}$ & $\begin{array}{l}\text { severi } \\
\text { neveri } \\
\text { mean of } \\
\text { s. } \\
\text { s of ob } \\
\text { an squa }\end{array}$ & $\begin{array}{l}\text { rved er } \\
\text { icted er } \\
\text { on pre } \\
\text { or desc }\end{array}$ & $\begin{array}{l}\text { erity. } \\
\text { erity. } \\
\text { ysten }\end{array}$ & unsy & c errc & ectively & & & & \\
\hline
\end{tabular}




\section{DISCUSSION}

Weather conditions during early flowering and floret sterility have been identified as the major factors affecting the severity of ergot in grain crops. Gupta et al. (9) reported that rainfall, sunshine hours, relative humidity, and air temperature accounted for $95 \%$ of the variation in the ergot (C. fusiformis) infection index of pearl millet. The latter two variables accounted for $80 \%$ of the variation in disease severity. Similarly, Thakur et al. (15) reported that temperature and panicle wetness were the major variables affecting ergot severity. The high $R^{2}$ value obtained between ergot severity, temperature, and relative humidity in this study, as well as results from previous studies $(2,11,12)$, reaffirms the close relationship between weather variables and ergot severity in sorghum. Results of this study also indicate that a model based on temperature and relative humidity can accurately predict mean ergot severity in a genetically broadbased sorghum nursery.

It is essential to note that the ergot potential prediction model derived in the present study assumes the presence of abundant, viable inoculum and is, therefore, limited to artificial epidemics rather than natural epidemics. The aim of the present study was to determine an alternate

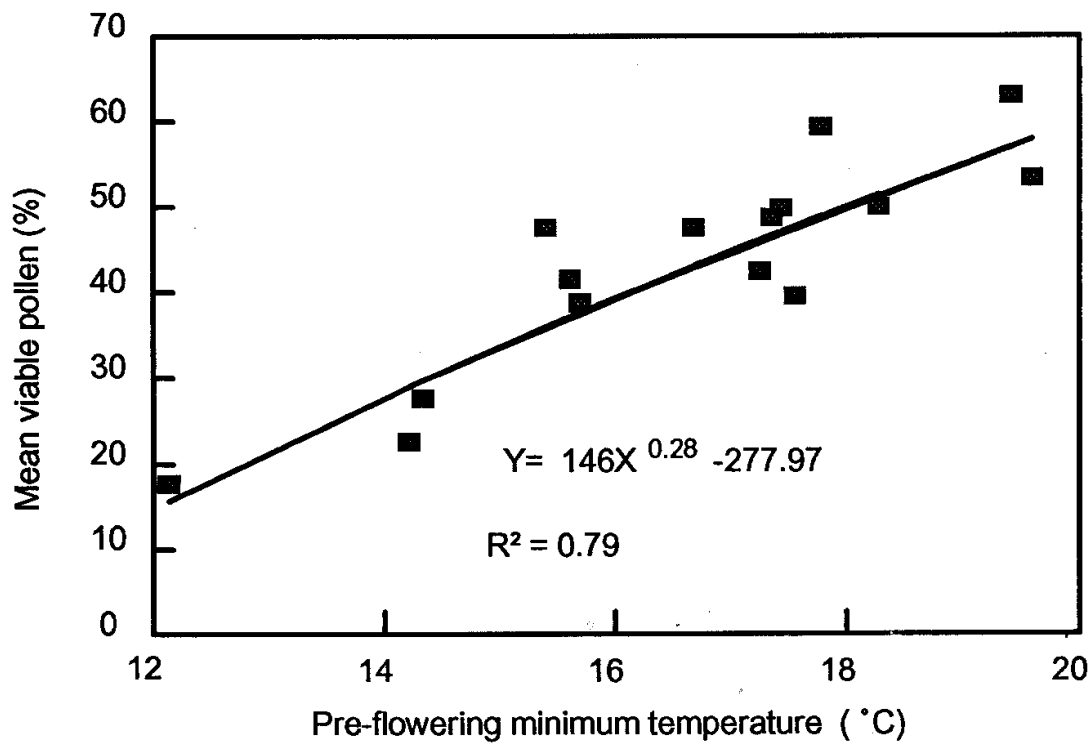

Fig. 1. Relationship between pollen viability in a genetically broad-based sorghum nursery and mean minimum temperature 23 to 27 days pre-flowering during 1990 to 1991 and 1992 to 1993 growing seasons in South Africa.

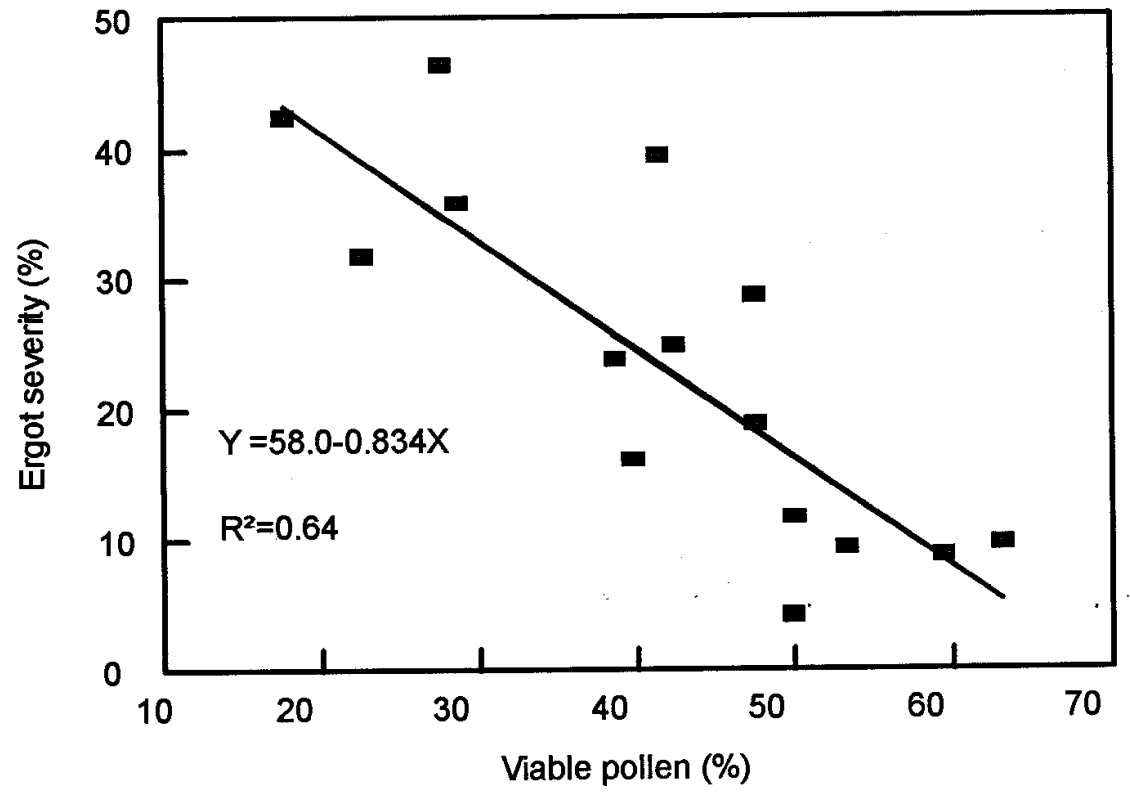

Fig. 2. Relationship between pollen viability and mean ergot severity caused by Claviceps africana in a genetically broad-based sorghum nursery during 1990 to 1991 and 1992 to 1993 growing seasons in South Africa. means of quantifying the ergot potential under which resistance screening is conducted, which would reduce the necessity for large numbers of diverse lines, field trials, and labor requirements. The predicted ergot potentials obtained in the present study appear sufficiently accurate for future use as an index against which to measure line reactions to ergot.

Predisposition of florets by pre-flowering cold stress, as indicated by decreased pollen viability in the present study, is a significant factor in the severity of ergot epidemics. The relatively high $R^{2}$ value for the relationship between pollen viability and ergot potential $\left(R^{2}=0.64\right)$ suggests that variation in ergot potential appears to be largely the result of the interaction of pre-flowering low temperature effects on pollen viability, and confirms earlier suppositions (11). This relationship requires further elucidation. Musabyimana et al. (13) plotted the relationship between time of inoculation relative to anthesis and ergot incidence and found a $8.3 \%$ increase in disease for each day's delay in anthesis after inoculation. Similarly, Thakur et al. $(16,17)$ and Darlington and Mathre (5) reported relationships between pollination rate and ergot incidence in millet and wheat, respectively, with increased disease severity as pollination is delayed. Futrell and Webster (8) found increased susceptibility of sorghum to ergot in male-sterile lines compared with male-normal lines. Brooking (3) recorded reduced pollen viability with increased pre-flowering cold stress of sorghum and, subsequently, evidence that prolonged pre-flowering cold stress may reduce female fertility (4). The role of reduced male and/or female fertility and the possible interaction effects of these forms of fertility on ergot susceptibility need further study.

The model developed in the current study appears to consider weather effects during the infection processes as well as plant predisposition (increased sterility) on the severity of ergot. The ergot potentials predicted by the model are accurate enough for determination of ergot breakdown points of lines and, therefore, the determination of tolerance of lines to ergot-favorable conditions. The simplicity of the model in determining ergot potential, together with the elimination of large trials and diverse lines, makes it an ideal tool for use in sorghum ergot screening trials.

\section{LITERATURE CITED}

1. Bandyopadhyay, R., Frederickson, D. E., McLaren, N. W., and Odvody, G. N. 1996. Ergot - a global threat to sorghum. Int. Sorghum and Millets Newsletter 37:1-32.

2. Bandyopadhyay, R., Mughogho, L. K., Manohar, S. K., and Satyanarayana, M. V. 1990. Stroma development, honeydew formation and conidial production in Claviceps sorghi. Phytopathology 80:812-818.

3. Brooking, I. R 1976. Male sterility in Sorghum bicolor (L.) Moench induced by low night temperature. I. Timing of the stage of 
sensitivity. Aust. J. Plant Physiol. 3:589596.

4. Brooking, I. R. 1979. Male sterility in Sorghum bicolor (L.) Moench induced by low night temperature. II. Genotypic differences in sensitivity. Aust. J. Plant Physiol. 6:143147.

5. Darlington, L. C., and Mathre, D. E. 1976. Resistance of male sterile wheat to ergot as related to pollination and host genotype. Crop Sci. 16:728-730.

6. Frederickson, D. E. 1990. Ergot disease of sorghum. Ph.D. thesis, University of London, London, UK.

7. Frederickson, D. E., and Mantle, P. G. 1988. The path of infection of sorghum by Claviceps sorghi. Physiol. Mol. Plant Pathol. 33:221-234.

8. Futrell, M. C., and Webster, D. J. 1965. Ergot infection and sterility in grain sorghum. Plant Dis. Rep.49:680-683.

9. Gupta, G. K., Subbarao, K. V., and Saxena,
M. B. L. 1983. Relationship between meteorological factors and the occurrence of ergot disease (Claviceps microcephala) of pearl millet. Trop. Pest Manage. 29:321-324.

10. McLaren, N. W. 1992. Quantifying resistance of sorghum genotypes to the sugary disease pathogen (Claviceps africana). Plant Dis. 76:986-988.

11. McLaren, N. W., and Wehner, F. C. 1990. Relationship between climatic variables during early flowering of sorghum and the incidence of sugary disease caused by Sphacelia sorghi. J. Phytopathol. 130:82-88.

12. McLaren, N. W., and Wehner, F. C. 1992. Preflowering low temperature predisposition of sorghum to sugary disease (Claviceps africana). J. Phytopathol. 135:328-334.

13. Musabyimana, T., Sehene, C., and Bandyopadhyay, R. 1995. Ergot resistance in sorghum in relation to flowering, inoculation technique and disease development. Plant Pathol. 44:109-115.
14. Sundaram, N. V. 1980. Sorghum ergot. Pages 377-379 in: ICRISAT (International Crops Research Institute for the Semi-Arid Tropics). Proc. Int. Workshop on Sorghum Diseases, sponsored jointly by Texas A \& M University and ICRISAT, 11-15 December 1978, Hyderabad, India

15. Thakur, R. P., Rao, V. P., and King, S. B. 1991. Influence of flowering event factors in cytoplasmic male sterile lines and F1 hybrids on infection by Claviceps fusiformis in pearl millet. Plant Dis. 75:1217-1222.

16. Thakur, R. P., and Williams, R. J. 1980. Pollination effects on pearl millet ergot. Phytopathology 70:80-84.

17. Thakur, R. P., Williams, R. J., and Rao, V. P. 1983. Control of ergot in pearl millet through pollen management. Ann. Appl. Biol. 103:3136.

18. Wilmott, C. J. 1982. Some comments on the evaluation of model performance. Bull. Am. Meteorol. Soc. 63:1309-1313. 